\title{
PHENOMENOLOGY AND MEDIA LITERACY
}

\author{
Çise AYHAN \\ $\mathrm{Ph}$.D. Student, University of Vienna \\ ciseayhan@gmail.com \\ Zrinka DOMITRAN \\ Ph.D. Student, University of Vienna \\ zrinka.domitran@gmail.com \\ Nikola RADUNOVIC \\ Ph.D. Student, University of Vienna \\ indoktrinacija@yahoo.com \\ Sepehr Dadjoi TAVAKOLI \\ $\mathrm{Ph}$.D. Student, University of Vienna \\ tavakoli.d.s@gmail.com
}

\begin{abstract}
Is phenomenology a movement or concept? Is it a research method in human science? Different approaches have been introduced with the term of phenomenology, even it has been named as movement.It is commonly understood in either of two ways: as a disciplinary field in philosophy, or as a movement. In phenomenologist's point of view, "Phenomenology is the theory of experiences in general, inclusive of all matters, whether real or intentional, given in experiences, and evidently discoverable in them" Phenomenology demands that we seek to discover the world as it is experienced by those involved in it. It is about the nature of human experience and the meaning that people attach to their experiences. The axis of phenomenology is discussion about conscious, the conscious which becomes manifest in mind without any median and prejudice. Media literacy is a gate for this conscious and maybe we can say that considering circumstances of contemporary life in third millennium and modern society that are ensuring concept of media literacy, without media literacy this conscious is distorted. In this regards, the research paper attempts to analyse the term of phenomenology and its relation to media literacy. In this regards, what is discussed in this study is as follows: 'What is the meaning of Phenomenology', 'What is the position of the term?', 'Who are the most important researchers on this field?', What is the usibility of the topic', 'To what extend has the phenomenology been used by media literacy?'
\end{abstract}

Keywords: Phenomenology, Media Literacy, Philosophy, Media, Disciplinary Field

\section{FENOMENOLOJİ VE MEDYA OKURYAZARLIĞI}

\section{ÖZ}

Fenomenoloji (görüngü bilim), tanımı üzerine birçok görüş olmakla birlikte, bir felsefi akım olmanın yanında bir yöntem olarak da tarif edilir. Husserl'e göre, bir öz ontolojisi olan fenomenoloji, bütün bilimlerin temelinde yer alır. O, çeşitli bilimlerin köklerinin bulunduğu nötr bir araştırma alanı olarak felsefe, psikoloji ve mantığın doğrudan doğruya, öteki bilimlerin de dolaylı olarak temelindedir. $\mathrm{Bu}$ bağlamda, çalışmanın ilk bölümünde, fenomenolojik yöntem ve öz kavramı üzerinde durulmuş, görüngü bilim tanımlanmaya çalışılmıştır. Çalışmanın ikinci bölümünde fenomenolojik yöntem tarihsel süreç içerisinde irdelenmiş ve ardından gelen birçok düşünürü etkileyen ve fenomenolojinin kurucusu olarak görülen Husserl'ın fenomenoloji hakkındaki görüşleri ve bu yöntem üzerinde çalışan 
diğer düşünürler okuyuca aktarılmıştır. Daha sonra, disiplinin kullandığı metodlar ele alınmış; son bölümde ise medya-fenomenoloji ilişkisi analiz edilmeye çalışılmıştır.

\section{Anahtar Sözcükler: Fenomenoloji, Görüngü Bilimi, Fenomenolojik Yöntem, Medya, Medya Okuryazarliğl}

\section{INTRODUCTION}

Is phenomenology a movement or concept? Is it a research method in human science?

Different approaches have been introduced with the term of phenomenology, even it has been named as movement (the Phenomenological movement; A Historical Introduction by Herbert Spiegelberg 1960). It is commonly understood in either of two ways: as a disciplinary field in philosophy, or as a movement. Generally, phenomenology has never been defined under a philosophical flow, but it has always been claimed that it is a radical approach and instead of being a "philosophize system" is a "philosophical practice" (the Encyclopedia of Philosophy 1967 by Paul Edwards (Phenomenology Essay by Richard Schmitt). According to such as discussion, providing a quiddity of phenomenology is simple and complex. With deeper perspective, phenomenon is basically a philosophical term which is realized differently in different subjects, whereas it is something which appears in direct experiences. In this regard, the discipline of phenomenology may be defined initially as the study of structures of experience, or consciousness.

The research paper attempts to analyse the term of phenomenology and its relation to media literacy. In this regards, what is discussed in this study is as follows: 'What is the meaning of Phenomenology', 'What is the position of the term?', 'Who are the most important researchers on this field?', What is the usibility of the topic', 'To what extend has the phenomenology been used by media literacy?' Based on the landscape of the area, the research has been done with four parts which consist of the explanation of the term, historical background and the methodological aspect of the issue and as a last part, the relation to media literacy.

\section{The Discipline of Phenomenology}

In phenomenologist's point of view, phenomenology started in the 1900s with the publication of Edmund Husserl's Logical Investigations. Phenomenology pertains to a critical method of reflection on consciousness and attempts to address the question of value, the meaning of being, existence, and the lived body. According to Winkler (2013), phenomenology is a timely philosophical practice and tradition compared to the empiricist, rationalist and Kantian ways of doing philosophy. It has been the object of critical and creative analysis since the publication of Husserl's Logical Investigations.

Husserl defined phenomenology as a philosophical term devoted to experience, Phenomenology represents the refusal to see being outside of the rubric of the experience of it. He stressed, "Phenomenology is the theory of experiences in general, inclusive of all matters, whether real or intentional, given in experiences, and evidently discoverable in them" (Husserl, 1991). Husserl's early work stresses the importance of logical structure. Husserl gives priority to experience. Phenomenology takes on the metaphysical failure to address the priority of experience in its understanding of being. Metaphysics focuses on questions of knowledge about being and it does not question how being becomes as a possible object of knowledge (Husserl, 1991). Emmanuel Levinas(2015) states that in Phenomenology, "the various problems of knowledge are reduced to the problem of how objects are constituted by consciousness".

Phenomenologists start with experience in order to understand being rather than understand experience in terms of their conception of being. They share a belief that metaphysics from Plato onward has excluded experience and temporality, and the result has been a hypostatized conception of being, As a consequence, the rigid categories of thought are permitted to influence the nature of being. Metaphysical thought is unable to grasp the inherent temporality of being, but phenomenology is able to do this by privileging time at every turn. As Heidegger notes in The Basic Problems of Phenomenology, "time is the horizon from which something like being becomes at all intelligible. We interpret being by way of time" (Heidegger, 1982). A person's ability to access and understand being 
depends on our awareness of its essential temporality. People essentially experience being through time (MacGowan, 2013).

Phenomenology responds to the fundamental metaphysical violence against time. Metaphysics subordinates temporality to knowledge and thereby reduces the incessant movement of time, which knowledge cannot grasp, to moments of presence, which it can. Phenomenology is a specific effort to break free from this reduction of time to knowledge. Derrida's initial analysis of the trajectory of Husserl's thought in The Problem of Genesis in Husserl's Philosophy that he understands phenomenology in this way. In his philosophical career, Husserl has to surmount a stumbling block because, as Derrida sees it, he has not fully grounded his thought in the experience of temporality. Derrida claims that "It is because Husserl does not yet place originary temporality at the core of his descriptions that the dialectic of unity and multiplicity fails and with it the whole transcendental project" (Derrida, 2003). In his subsequent work, Husserl will correct this problem, and the progress of phenomenology will be characterized by a marked awareness of our originary temporality and an attempt to think beyond the metaphysics of presence.

A point of concern of phenomenology is freeing experience from the burden of knowledge that deforms and hides it from us. Husserl renders that logical structure, rather than constituting our experience, represents a barrier to it. A person's experience has a sense that constitutes it outside of the layers of mediation that pollute our thinking about this particular experience. For example, I experience the books on my desk, and then my thinking mediates that experience with the knowledge that I have about the content of the books, which has the consequent impact of deforming the relationship by having an impact on the immediacy of the initial perception. This deforming process occurs in philosophical reflection about the nature or essence of the books (McGowan, 2013).

A basic premise of phenomenology is that an unmediated experience exists. Then persons can have access to it. This is the main distinction that Hegel, as a metaphysician, would reject. Husserl develops the phenomenological reduction, which brackets the knowledge and preconceptions that we bring to experience in order to allow us to understand the true nature of that experience. The reduction serves as a countermeasure to the role that theorizing plays in misshaping experience. Husser wrote in his Cartesian Meditations, "phenomenological explication does nothing but explicate the sense this world has for us, prior to any philosophizing, and obviously gets solely from our experience-a sense which philosophy can uncover but never alter, and which, because of an essential necessity, not because of our weakness, entails horizons that need fundamental clarification" (Husserl, 1991).

The immediate sense of our experience is blurred by theories. The entire project of phenomenology as a corrective to metaphysics is based on this belief that a pre-theoretical consciousness exists and that one can access it. The metaphysical error, does not refer to identifying being with presence but instead failing to think fully enough the possibility of presence in experience. Metaphysics loses itself in the mediation of knowledge and theory, thereby blinding itself to the experiential source of all knowledge. Ideas do not give shape to life; they represent layers of sedimentation that disguise life.

In order to better understand, we can mention an elementary exercise in phenomenology, consider some typical experience one might have in everyday life, characterized in the first person. For instance, from the standpoint of the natural attitude, a minute of time is simply a minute of time, regardless how and where we spend it. However, from the point of phenomenological attitude, a minute of time depends on how we actually experience it. For example, a minute of time may pass very quickly, if you are excited or happy, or very slowly if you are bored. Hence, it is stated as upshot which it the meaning of things varies quite a bit, depending upon whether we are seeing them from the natural attitude or from the phenomenological attitude.

In this regards, the benefits associated with the phenomenological attitude includes better understanding of meanings attached by people and its contribution to the develop. However, there are some limitations associated with the term of phenomenology are summarized on the following table by Armstrong (2010) as taken from Easterby-Smith et al (1991). 


\begin{tabular}{|l|l|}
\hline Benefits of Phenomenology & Limits of Phenomenology \\
\hline It can look at change processes over time & $\begin{array}{l}\text { Data gathering can take up a great deal of time } \\
\text { and resources }\end{array}$ \\
\hline It helps to understand meanings & $\begin{array}{l}\text { The analysis and interpretation of data may be } \\
\text { difficult. }\end{array}$ \\
\hline $\begin{array}{l}\text { It helps to adjust to new issues and ideas as they } \\
\text { emerge }\end{array}$ & $\begin{array}{l}\text { It may be hard to control pace, progress and end } \\
\text { points }\end{array}$ \\
\hline It contributes to the development of new theories & $\begin{array}{l}\text { Policy-makers may give low credibility to } \\
\text { phenomenological study }\end{array}$ \\
\hline
\end{tabular}

As a result, there are various assumptions about phenomenology that attempt to explain its foundations. First,it rejects the concept of objective research. Phenomenologists prefer grouping assumptions through a process called phenomenological epoche. Second, phenomenology believes that analyzing daily human behavior can provide one with a greater understanding of nature. The third assumption is that persons, not individuals, should be explored. This is because persons can be understood through the unique ways they reflect the society they live in. Fourth, phenomenologists prefer to gather "capta," or conscious experience, rather than traditional data. Finally, phenomenology is considered to be oriented on discovery, and therefore phenomenologists gather research using methods that are far less restricting than in other sciences.

\section{Historical Background of the Phenomenology}

"History is useful not because we can see the past in it - but because we can see the future"

(Jean-Baptiste Say)

In order to better comprehend phenomenology as a philosophical movement, we must understand how it came about and the people who created and marked it. When Hindu and Buddhist philosophers considered the state of consciousness in various meditative states, they practised phenomenology. The term 'phenomenology' first appeared as a term in scientific and philosophical literature as early as 18th century. In his work entitled New Organon (1764), the philosopher Lambert calls phenomenology "the doctrine of appearance" and its role in preventing the human thought from reaching the truth. (The Miroslav Krleža Institute of Lexicography). In this sense, we find the term 'phenomenology' in the writings of J.G.Herder, J.G. Fichte and G.W.Hegel, who in 1807 authored his famous "The Phenomenology of Spirit" as the depiction of "the process by which science in general comes about". In his "Critique of Pure Reason", Kant shows how the attempts to use reason to establish metaphysical "truths" always produce impossible contradictions. Then he proves how we perceive the world. The human mind is an active, rather than a passive recipient of perception. When looking at the world, we "constitute" it in order to make sense of it.

Certain concepts we apply to our everyday experience truly originate from the previous ones, but the most important ones precede experience. They are the a priori experiences.

David Hume claimed that we gradually build up our conceptual apparatus from our experiences, to which Kant replied that "unless we have some mental conceptual apparatus, no experiences would ever be possible".

"Thoughts without contents are empty, intuitions without concepts are blind." (Immanuel Kant, Critique of Pure Reason)

This created the concepts of the phenomenal and noumenal (real) world. Furthermore, it is important to point out that all experience is achieved through "sensory forms of space and time" (Tom Rockmore, "Kant and Phenomenology", University of Chicago Press, 2011). Thus our experience of the world is our own creation, which we edited on our own.

"But what are we trying to achieve in experience?" 
Phenomenology is an attempt to answer this question; it focuses on analysing the ways in which things come about in our awareness "Why do we pay attention to the thing we pay attention to." Before discussing the founder of phenomenology, Edmund Husserl, after which we will be able to split the timeline "before Husserl" and "after Husserl", we must mention two philosophers who influenced Husserl. The philosopher and psychologist Franz Brentano proposed "descriptive or phenomenological psychology" and introduced the concept of "intent" (if there is memory, there is memory of something, if we are looking at something, there is something we are looking at...).

The mathematician and philosopher Rene Descartes based his beliefs on doubt, he started doubting everything, even laws of mathematics. He believed that he found a method allowing him to perceive truths that are so self-evident that they cannot be doubted (Shahabi Zia 1998, Hermes Teheran, phenomenological introductio to Philosophy Descartes). His fundamental attitude was "Cogito ergo sum", which means that the only path to real perception is questioning one's own awareness. His "cogito" does not represent awareness as simply thinking, but as reflecting on such thinking.

"Edmund Husserl reacted to his teachings on "questioning one's own awareness" by asking the question "what is awareness"?

Edmund Husserl (1859-1937)

Husserl is the founder of the philosophical movement called Phenomenology. He started his university education in Leipzig, where he studied astronomy; afterwards he attended the University of Berlin, where he studied mathematics. He continued his study of mathematics at the University of Vienna, where he defended his doctoral dissertation entitled "Beitrege zur Theorie der Variationsrechnung". After completing his education, he obtained the title of Privatdozent at the University of Halle. At the turn of the century, he published his work entitled "Logical Observations", where he introduced the notion of phenomenology in the sense of analysing subjective experiences. In his beginnings phenomenology is featured only in a reflective attitude, in a conceptually critical attitude towards mental or cognitive events.

Phenomenology discards all questions and describes ideas as the content of awareness.

Later phenomenology became presentation of experiences, not only from their physical side, but also towards their actual sense. It eliminates empirical research and focuses on the meaning of awareness. Experiences become thematic according to their "intentionality". For Brentano intention means to be focused on something, while Husserl starts with that concept, but changes it into an analytical problem. For example ANALYSIS OF PERCEPTION. The realm of an actual object everyone in a classroom can see the teacher's desk, but each from their place, left or right... but they can see only one side.

Husserl also works as the editor of the "Logos" magazine and holds classes entitled "Grundprobleme der Phennomenologie". In 1913 he penned his work entitled "Ideas on a Pure Phenomenology and Phenomenological Philosophy". This work converted phenomenology to a philosophical method. Husserl's phenomenology aims to observe the essence of things and develops the "science on the phenomenon".

In his later teachings Husserl steers phenomenology towards a more practical, that is, existential dimension of the human knowledge. In his work entitled "Krisis der Europeaischen Wissenschaften" he focused on the "natural world" and the "nature of social existence"; these concepts had played a small role in his teachings up to that point, but are of great importance for the "existential phenomenology" that would follow. 1936 sat the beginning of strict political measures imposed by the nationalist socialistic regime and Husserl was banned from teaching and taking part in the 9th International Philosophers' Congress in Paris (1937).

Shortly after he died after a long illness, and his legacy is saved by H. L. Van Breda. (Science Enciyclopedia).

After Husserl, his students continued to develop phenomenology in their corrections and directions. One of them was Martin Heidegger(1889-1976), theologian and philosopher who based his work on the very "being" of human existence. He is one of the most respected 20th century philosophers. After 
the publication of his work "Being and Time" (1927), he became the centre of philosophical discussions. In this book the advocates the philosophical opinion directed primarily towards the "meaning" or "truth of being".

According to Heidegger, philosophy should deal with being, because that issue passed into oblivion under the influence of civil subjectivism. Heidegger dealt with the problem forgotten by his teachers, Husserle and Descartes, and that is that I exist in this world as long as I am alive. He founded fundamental ontology, he made the man the guardian of being because only man can comprehend its truth and meaning. He wrote many essays, but he never managed to finish the second part of his work "Being and Time". Due to his political beliefs and joining Hitler's National Socialist Party, he left the philosophical scene and retired.

In addition to Husserl and Heidegger, another two representatives of phenomenology hold an important part of history: Merleau-Ponty and Jean-Paul Sartre.

Merleau-Ponty(1908-1961) worked in France; in his work entitled "Phenomenology of Perception". He developed the role of the human body in experience as an important factor.

He does not separate the mind and the body, but rather develops "body image" as the experience of the body and its meaning in our activities.

In addition to being a philosopher, Jean-Paul Sartre(1905-1980) was a great writer; he penned many novels and was awarded the Nobel Prize. In his works he developed his concept of phenomenological ontology. He took over Husserl's idea that "awareness is the awareness of objects", but to Sartre "I" is a series of acts of awareness. He employed a literary style that interpreted different kinds of experiences in different situations.

Due to the widespread nature of the phenomenological movement, globally phenomenology developed in different directions, which is why we have:

- transcendental phenomenology, founded by E .Husserl,

-ontological phenomenology of the Gottingen and Munich circles,

- existential phenomenology of M. Heidegger

- hermeneutical phenomenology of H. G. Gadamer

- lifeworld" phenomenology of late Husserl,

surpassing the "Crisis of European sciences" and paving the way towards historical thinking.

Despite these differences there is a complex communication.

- All the phenomenologists accept intencionality although some interpret differently.

- Philosophy for doing its duty has to do specially "epoche". It means a fundamental change in the approach that bring back philosopher to the meaning.

- All of the phenomenologists agree that the main occupation of Philosophy is to answer the question of meaning and existing of creature.

\section{Phenomenological Research}

"I want to understand your world through your eyes and your experiences so far as possible, and together we can probe your experiences fully and understand them." (Bate \& Robert 2007, 37)

The question is: What methods are appropriate to phenomenological research? Phenomenology demands that we seek to discover the world as it is experienced by those involved in it. It is about the nature of human experience and the meaning that people attach to their experiences. In trying to arrive at this kind of understanding, the researcher is asked to 'bracket', or suspend belief in the phenomena of the external world, to put them aside and focus on the consciousness of that world. Consequently, phenomenology is not a hypothesis testing mode of research, nor is it one that must be guided by theoretical models. Rather, one is urged to get as close as possible to what the participants in the behaviour of interest are experiencing.

Dilthey (1977) classified the various methodologies under the categories of natural sciences and human sciences. The natural science approaches are founded upon the ontology and epistemology of the Enlightenment's empiricism in the 17 th century and logical positivistic philosophy in the 19th century. The human science approaches, on the other hand, are founded upon the ontology and epistemology of rationalist and phenomenological philosophy. They utilize ethnographic, descriptive, interpretive, and collaborative methodologies (commonly referred to as qualitative methodologies), with their focus upon understanding the totality of experience as it is lived and presents itself preceding its formulation by the scientific community. However, beginning in the 20 th century within 
the natural sciences themselves, positivism has been critiqued extensively. With theorists such as Einstein and Heisenberg, the fundamental influence (and indispensable bias) of the observer entered into natural scientific inquiry (Kuhn, 1970). Natural science theorists (e.g., Kuhn, 1991) began to argue that contem-porary science has forgotten its foundation as residing in experience, and has become a world of idealized mathematics.

As one of the great philosophers of the twentieth century, Husserl introduced and developed phenomenology as an alternative epistemology and methodology for the natural and human sciences. Husserl's (1970) philosophical aim was to develop an epistemology which can be applied to all fields of knowledge, founded upon the primacy of consciousness and the argument that there is an epistemological priority to "the essence of what something is and how it comes about" in contrast to "the reason that (or why) something is," and thus explanation requires the "what" and "how" of the phenomenon (Karlsson, 1993). Husserl defined consciousness as an intentional act of revealing which is fundamental to human nature. He argued that, when we examine a particular phenomenon, we should let the phenomenon "speak for itself" and allow it to reveal or manifest itself in consciousness. Phenomenology was developed to study the meanings of psychological phenomena for participants through their rich descriptions of their lived-experiences. The qualitative interview or protocol is the manner in which this is classically conducted. Human beings have an intentional relationship with their world and consciously and meaningful interrelate with it. As the "objects" of study, human beings are subjects being studied by subjects, both of whom meaningfully intend their "objective world." Human beings interpret their worlds and themselves (they are self-interpreting), and their actions are always bound up with beings-for-whom they are meaningful. Assuming that it is the intentional responses of participants (rather than determined reactions) that are examined (Giorgi, 1971), the goal for phenomenology is to grasp what these meanings are for their agents (Taylor, 1980).

Thus, phenomenology begins with an experience or condition and, through the narration of participants, of either a shared single incident or shared condition, investigates the effects and perceptions of that experience. "Phenomenologists distinguish phenomena (the perceptions or appearances from the point of view of a human) from noumena (what things really are) (Willis, 2007, p. 53). Simply, the phenomenological method interprets an experience or fact, by listening to the different stories of the participants. The method examines the phenomena through the subjective eyes of the participants. "Phenomenology (is) focused on the subjectivity of reality, continually pointing out the need to understand how humans view themselves and the world around them" (Willis, 2007, p. 53). Phenomenology offers a qualitative method of inquiry that can be applied to myriad of experiences. On a grand time scale phenomenology offers the researcher the ability to examine the different perspectives of participants of lengthy experiences such as those who survived the holocaust. Research conclusions do not investigate the holocaust as a phenomenon, but rather the experiences of the participants as they participated in that phenomenon, which in turn allows a deeper understanding of the phenomenon through examination of those experiences. However phenomenology also offers the researcher the ability to examine the cumulative experience of participants as they relate to a single point in time. "The focus is thus on understanding from the perspective of the person or persons being studied" (Willis, 2007, p. 107).

Some literature identify two types or elements to phenomenology, hermeneutic and transcendental or philosophical (Campbell, Introductive Methods to Qualitative Research: Course Notes, n.d., p. 4), (Creswell, 2007, pp. 59-60). Originally the term hermeneutics referred to the study of sacred texts such as the Talmud or Bible" (Willis, 2007, p. 104). Hermeneutics has expanded its meaning and focus over the years. "Gradually, hermeneutics has expanded beyond that original meaning to include understanding human action in context" (Willis, 2007, p. 104). In transcendental phenomenology "the researcher...analyzes the data by reducing the information to significant statements or quotes and combines the statements into themes" (Creswell, 2007, p. 60). From these themes the researcher "develops a textural description... what the participants experienced and a structural description...how they experienced it in terms of conditions, situations or context" (Creswell, 2007, p. 60). The combination of which "convey an overall essence of the experience" (Creswell, 2007, p. 60). This principle is essential to effective data analysis.

All research has methods or elements that define the validity of the research. Specific questions posed to the participants may vary and be framed on criteria based on the type of participant, the phenomenon being studied, or the purpose of the research in general, the basic outline of what is 
needed within the structure of phenomenology is universal. "Understanding often calls for different forms of research and different ways of reporting the results of research" (Willis, 2007, p. 108). Phenomenology through its methodology insures the validity of the results by structuring the focus of the research. Phenomenology constructs data by eliciting in-depth individual storytelling thereby garnering cumulative essence of the experience (Campbell, Introductive Methods to Qualitative Research: Course Notes, n.d., p. 4).

The first method in phenomenological research is identifying the phenomenon that will define the shared experience (Campbell, Introductive Methods to Qualitative Research: Course Notes, n.d., p. 4). What exactly is the phenomenon that is being studied? As we said, the phenomenon can take the form of events that took place over a period of years or a matter of seconds. Events can be further dissected into more specific experiences. One standard that should be considered is "Does the author have a clear "phenomenon" to study that is articulated in a concise way" (Creswell, 2007, p. 215). Regardless of experience, good phenomenological research must first identify the event or shared experience clearly. Identifying the phenomenon gives a vehicle to clarification of the first element of phenomenology "identification of the shared experience" (Campbell, Introductive Methods to Qualitative Research: Course Notes, n.d., p. 3). What experience was shared? Understanding the event and thereby the shared experience of that event by different participants leads a researcher to better understanding of that experience (Campbell, Introduction to Methods of Qualitative Research: Video Series, 2011) ${ }^{1}$. Once a phenomenon and the shared experience to be studied are identified the researcher must then ask the definitive question, regardless of method used "Is the research problem best examined using the phenomenological approach? (Creswell, 2007, p. 60). Employing the wrong research method would be likened to asking the wrong question. Little valuable understanding could be gained thereby invalidating the research. "The type of problem best suited for this form of research is one in which it is important to understand several individuals' common or shared experiences of a phenomenon" (Creswell, 2007, p. 60).

The second step in the methodology of phenomenological research is, "bracket and interpret researcher bias and expectations" (Campbell, Introductive Methods to Qualitative Research: Course Notes, n.d., p. 4). This is identified as a best practice of the method (Campbell, Introductive Methods to Qualitative Research: Course Notes, n.d., p. 4). The bias of the researcher in any research method can taint the results. Phenomenology is no different. It is therefore a sound practice to identify, both from a researchers point of view, areas that could create bias and thereby nullify the research conclusions. A researcher's bias regarding the phenomenon being studied could lead to a misinterpretation of the data and erroneous conclusions, regardless of the detail and thoroughness or the research. As difficult as it may be, researchers must attempt to limit their personal bias and approach the phenomenon with an open mind (Creswell, 2007, pp. 59-60). Identification of the researcher's personal bias or expectations is known as "epoche" or bracketing (Creswell, 2007, p. 59). Before research is begun a discussion of the researcher's interpretations of the phenomenon, prior to the beginning of research, must be identified. As described by Creswell (2007), although this process is never perfect, "I see researchers who embrace this idea when they begin a project by describing their own experiences and bracketing out their views before proceeding with the experience of others" (Creswell, 2007, p. 60). As seen from the citations above, a researcher could, and probably does have some contextual knowledge or understanding of the phenomenon being studied thereby creating a preresearch bias on the part of the researcher. Therefore bracketing is essential to limiting researcher biased conclusions to research data which should only consider the perspectives of the participants (Creswell, 2007).

Following successful bracketing, the next step to the phenomenological method is to collect the data. The project outcome is dependent on careful selection of the participants for the research. In theory the more participants a research project has, the better the researchers understanding of the experience should be (Campbell, Introduction to Methods of Qualitative Research: Video Series, 2011) ${ }^{2}$.

\footnotetext{
$1 \quad$ Video 11

http://www.youtube.com/watch?v=LLjKdvVzKXM\&feature=bf next\&list=PL809EFFA210C27775\&lf=BF a

$2 \quad$ Video 11

http://www.youtube.com/watch?v=LLjKdvVzKXM\&feature=bf next\&list=PL809EFFA210C27775\&lf=BF
} 
Likewise the demographics of the participants are also important to understanding the nature of the data. The more demographically similar the participants are the better a researcher's ability to understand the "general" nature of the experience can be defined (Campbell, Introduction to Methods of Qualitative Research: Video Series, 2011) ${ }^{3}$. The demographics of the participants can be narrowed to any practical extent so long as a sufficient number of participants are available to validate the study. It is therefore important to frame the demographics of participants without eliminating so many participants through narrow demographics as to make the collection of data impossible.

Through the collection of data the researcher must also identify the second element of phenomenological research, of "locating the universal nature of an experience" (Campbell, Introductive Methods to Qualitative Research: Course Notes, n.d., p. 3). This step is critical for a valid and successful research project. "To assess the quality of a phenomenology... Does the author convey the overall essence of the experience of the participants? Does the essence include a description of the experience and the context in which it occurred? (Creswell, 2007, pp. 215-216). In other terms are the textual and structural descriptions available? Creswell (2007) identifies two focused questions necessary to collect relevant data necessary for sound analysis, "What have you experienced in terms of the Phenomenon? and "what contexts or situations have typically influenced or affected you experience...? (Creswell, 2007, p. 61). The importance of these focused questions in the success of the phenomenological research is made clear. "Other open-ended questions may be asked, but these two, especially, focus attention on gathering data that will lead to a textual...and structural description of the experiences, ultimately provide an understanding of the common experiences of the participants" (Creswell, 2007, p. 61). According to Campbell best practices in questioning should include three distinct elements. "Questions should draw from a common theme, questions should urge participants to identify the affect the phenomenon had on their lives, and questions should seek to identify the importance of interpreting the experience in a unique way".

Data analysis includes the highlighting of "significant statements, sentences, or quotes that provide an understanding of how the participant experiences the phenomenon" (Creswell, 2007, p. 61). Creswell said that data can lead to numerous interpretations of participants experiences, it is therefore necessary to "develop clusters of meaning from the significant statements into themes". As described earlier, at this point the practice and descriptions of transcendental phenomenology become relevant. Statements and themes developed from the "clusters of meaning" are then used to develop "descriptions of what the participant experienced, or textural descriptions, and descriptions describing the context or settings that influenced the experience, or structural descriptions" (Creswell, 2007, p. 61). From these separate structural and textural descriptions "unification into one structural and textural description gives a unified descriptive account" (Campbell, 2011).

"A phenomenology provides a deep understanding of a phenomenon as experienced by several individuals" (Creswell, 2007, p. 62). The data and insight gained from a phenomenology study can be invaluable. However, phenomenology has its pitfalls. Epoche or the bias of the researcher can damage a research project. Questions must be framed properly to allow proper data to be collected. "The participants in the study need to be carefully chosen to be individuals who have all experienced the phenomenon in question" (Creswell, 2007, p. 62). And finally, the data must be processed properly to "so that the researcher, in the end, can forge common understanding" (Creswell, 2007, p. 62).

There is much debate in phenomenological circles as to the 'method' of research one should use in a phenomenological enquiry. What is quite clear, however, is that there is no single method that will suffice for all and every enquiry. Phenomenological researchers agree on some basic guidelines and indicate that the approach to a phenomenological method design should be a two-fold procedure consisting of the epoché or bracketing and the eidetic reduction. Both steps are essential to phenomenological methodology. Bracketing consists of suspending ones 'natural attitude', or our taken-for-granted approach to everyday living informed by culture and education, including our "past

a

Video 12

http://www.youtube.com/watch?v=SqyixDFO904\&feature=BFa\&list=PL809EFFA210C27775\&lf=BFa

Submit Date: 15.02.2016, Acceptance Date: 27.03.2016, DOI NO: 10.7456/10602100/003

Copyright $\mathbb{C}$ The Turkish Online Journal of Design, Art and Communication 
knowledge of the phenomenon encountered" (Giorgi, 1997, p. 240). Bracketing requires a rigorous reflection on one's bias, opinions, and cultural and socio-economic backgrounds.

\section{Consciousness}

For phenomenologists, perhaps the single most important assumption about human beings is that consciousness is the sine qua non of human life.

\section{Elimination of Dualisms}

The second important assumption of phenomenology is the belief that in consciousness, or the meaning making source of living, experiences are constituted holistically - there is no substantial difference between the subjective and objective world. This is because consciousness is always constituted in a reality that is not isolated from the experiential world. This assumption clearly breaks with the empirical tradition of dividing the world into material and nonmaterial, or the objective and subjective realms. Husserl wrote: "To the extent, however, that every consciousness is consciousnessof,' the essential study of consciousness includes also that of consciousness-meaning and consciousness-objectivity as such" (1965, p. 90). Hegel, who is often considered a forerunner of phenomenology, described the essential connectedness of the subjective and objective in consciousness: "What at first appeared as object is reduced, when it passes into consciousness, to what knowledge takes it to be, and the implicit nature, the real in itself, becomes what this entity per se is for consciousness ..." (1910/1967, p. 144).

Phenomenology has sometimes been viewed as being merely a subjective philosophy, but this is an erroneous interpretation. According to phenomenology, every act of consciousness contains the objective/subjective aspects of the same thing. In fact, phenomenology views the study of consciousness as the only access to the realities of the experiential world of human beings.

\section{Consciousness Is Temporal}

Another important assumption of phenomenology is that consciousness has a temporal aspect to it; each individual consciousness carries the lived experiences of the past within it as well as anticipations of the future. Essentially, there is no stopping point to consciousness in that along with its historicity and futuricity, it is always being reconstituted in new experiences. Whereas Husserl paid scant attention to the historical quality of consciousness, Heidegger (1931/1962) constituted his hermeneutics with an acute sense of the influence of time. He viewed human life as "thrown" into a way of being and giving meaning. A part of this assumption is the notion that experiences are lived before they are understood. Thus, it is in the "flow of life" that meanings are lived and only later brought to consciousness. This assumption naturally creates a tension with the positivist science goal of explaining structures of consciousness that are timeless and universal.

\section{The Cultural World Is a Creation of Human Meanings}

The last assumption to be addressed arises from the previous ones. The cultural world is a creation of the meanings human beings possess in consciousness. This assumption has two parts: (a) The cultural world is created through the meaningful connections each individual experiences in her or his contexts, and (b) cultural institutions are the creations that have emerged out of life activities. Thus phenomenological-hermeneutical study necessarily involves a study of the cultural systems in which individuals live. Culture is not something constructed outside of consciousness or the constitutions of meaning, but rather, is co-constructed in lived experiences both on the individual level and the group level.

Phenomenologists are interested in individuals as meaning makers, they study meaningful action rather than behavior. Within this distinction, action is viewed as being guided by values and motivations, whereas behavior is not. Barritt, Beekman, Bleeker, and Mulderij (1983) suggested that one of the goals of phenomenological research is to effectively communicate "the other's" way of seeing things.

Finaly we can say that the goal of this type of research is not to arrive at explanation, but rather to come to understand the processes that human beings engage in as they construct meaning from experiences. Phenomenological methods are judged by their usefulness in improving our understanding of human meaning making within a particular area of inquiry, not by their ability to 
lead to new discoveries or to verify laws. One of the difficulties of phenomenology is that the researcher is engaging in the description of meanings that always stand in relationships that are everchanging. The phenomenologists recognized this dilemma and responded to it in different ways. Husserl, for example, believed that through the collection of carefully selected individual cases in which the structures of consciousness become revealed, a systematic knowing of the ways human beings construct meaning could be elaborated.

At he end, as a researchers, we must always remember: "There is no progress in the sense of going from less true to more true. If there were such progress, we would always have to say in looking at the past that our ancestors erred, and forget that in the future we, too, will be ancestors" (van den Berg, 1999, p. 57)

\section{Media Literacy and Phenomenology}

Maybe it's just a claim but we never converge media literacy and phenomenology. Maybe it's just a fallacy. But it is worth to review. How and why we consider phenomenon and why we believe media literacy as a necessity to enter to new world.

The axis of phenomenology is discussion about conscious, the conscious which becomes manifest in mind without any median and Prejudice. Media literacy is a gate for this conscious and maybe we can say that considering circumstances of contemporary life in third millennium and modern society that are ensuring concept of media literacy, without media literacy this conscious is distorted. Thereupon phenomenography cannot have an accurate evaluation of phenomenon because actually media are able to manipulate phenomenon.

Phenomenology claims that revive of our link with reality, which is supposed to had no place in academic and philosophical debates of the nineteenth century, especially in Neo-Kantian tradition. In this fact arises this question: Why we pay attention to the thing we pay attention? (Heyer 2003:61). It means that no conscious occur in mind except pass from media society gate by media literacy.

The popular slogan of phenomenology is, there is not any cognition without theme of cognition. Therefore cognition is always cognition of something and in phenomenology it's called Intention or attention (Ahmadi hoseinali 2013).

Jean-Paul Sartre emphasis in his phenomenology on this point that although there is objective world out of us, but the truth of the world is conscious toward the world. Sartre has taken this phrase of philosophical phenomenology of Husserl and he knows exist of world depend on its exist in the mind of receiver (Khaleghi Damghani Ahmad,Nasr mehdi, series 43,No 1, 2013 p3-23).

Expression of cognition dose not manifest in vacuum, although philosophers do not give it authenticity but with media literacy definition and relying on agenda setting theory, it can be cited as a major gateway of phenomenology. This claim cannot be achieved unless with defining what media society is.

Although the concept of media society looks very tangible and familiar, but for many reasons the combination of these two words is neglected. There are many reasons enumerated but Couldry identifies three reasons in a classification.

First, until at least the early 1990s, most sociology and social theory neglected to say anything about media. Second, these crucial interventions in understanding how media later the possibilities of social organization did not inspire a broader set of investigations, for example about how media change sociology's other terms of reference. As a result, there is, as yet, no comprehensive account of how media change social ontology. Third, some sociologists have started to make media their priority, and particularly the technological base of media, but within a version of social theory that is unhelpful for understanding media and media's role in social life. (Couldy Nick, 2012, Media, Social, World)

This neglect and differentiation give not us a deep understanding of the effect of media society on conscious. Although there are written about media and its effect too much, but defining media society with phenomenological view, at first as an independent phenomenon and effective on conscious and second as source of conscious, is disregarded.

Most commentators believe that we are in the middle of a media revolution, centering on the internet's connection and transmission capacities and the countless digital media devices and infrastructures that have grown up around them. But the long history of myth making, about technology should make us cautions. (Couldry Nick 2012, Moscol 2009 , 117 ,compare Sconce 2003, plal fery and Gasser 2001-294, Morozov 2011) 
Its dimensions, results and effects are evaluated and approved by different theories. But this phenomenon is something more than common concepts of global village or information society, because the base of this phenomenon is effecting on individual conscious as a unit.

All of these discussion are summarized in agenda setting theory(McCombs 1972,2002,2005). But we have to assign this term far beyond of public agenda because we believe that media is far beyond. (McCombs, Maxwell (2004). Setting the Agenda: The Mass Media and Public Opinion). In fact media literacy as pillar of modern media society -that itself is a phenomenon and is evaluated by phenomenography - is a significant column for shaping and choosing conscious.

Media literacy is about to develop a vase ability in relation to the other symbolic systems consisting pictures and sounds. Today it is proposed that in modern world, media literacy is as valuable and important as the ability if traditional reading and writing for young people. Educator David Buckingham (2003) notes that media education is "the process of teaching and learning about media" and that media literacy is "the outcome - the knowledge and skills learners acquire." (David Buckingham, 2003, Media Education: Literacy, Learning and Contemporary Culture, pg.4)

The aim of media education is to develop critical understanding and active participation so that prepare young people to interpret and provide conscious judgment as media consumers. Although it is still push them to the media content producers. Media education is to develop innovative and critical abilities of young people.

This critical understanding can be communicational dimension of conscious. As Roger Silverstone (1999) argues, media literacy obviously entails a capacity to decipher, appreciate, criticize and compose, but it also requires a broader understanding of the social, economic and historical context in which texts are produced, distributed and used by audiences. As James potter defines a goal-based definition of media literacy and suggests that the main purpose of being more media literate is to have more control over the message and its interpretation at the time we face the messages other than anything else. If people have this ability they would control what is important in their life and they adopt their feedback expectations regarding to that important field (W.James Potter 2013, review of literature on media literacy)

Buckingham (- David Buckingham, Media Education: Literacy, Learning and Contemporary Culture, 2003, $204 \mathrm{pp)} \mathrm{mentions} \mathrm{that} \mathrm{"As} \mathrm{Zerrin} \mathrm{recognized,} \mathrm{the} \mathrm{attempt} \mathrm{to} \mathrm{separate} \mathrm{media} \mathrm{use} \mathrm{from} \mathrm{the} \mathrm{broader}$ context of the social practices and relationships in which it is situated is bound to result in a reductive account

\section{Methodology}

In the research, qualitative research method is utilised in order to seek information obtained in other studies and better understand/ the context/meaning of the term.

As Stake (2010) mentioned, qualitative research method is described as a mode of research aiming at clarifying ideas and enhancing insight regarding the research findings since they allow the exploration of a thorough depiction of phenomena.

In general it's a systematic review which is a protocol driven comprehensive review and synthesis of data focusing on a topic or on related key questions. It is typically performed by experienced methodologists with the input of domain experts. It'sevaluated primary view and data about quiddity and historical phenomenology. Moreover, with examine some theoretical frame work of media literacy is tried to converge as an interdisciplinary subject In this regards, the study was conducted in the lights of the provided literature. Books, articles and news related to journalism, online media, printing press and etc. are used as a source of information to be collected.

\section{Conclusion}

In all of these definitions mentioned in the research, the attempt is to connect with widespread level of phenomenon of media that its turn to clear phenomenon which its purpose is control of the noise on conscious. Indeed, the distance of literature and philosophy of media and communication cause the neglecting of some overlaps and divergences in this area.

With phenomenological point of view, it is easy to believe that media literacy is a phenomenon that can be evaluated by phenomenography. In other view, according to media literacy concept and categorization and around definitions, it can be predicated that this phenomenon as knowledge 
gateway especially in new era so that every analysis can be fault regardless effective changes of this gateway.

Barton and Hamilton (1998) defined media literacy: primarily something people do: it is an activity, located in the space between thought and text (cited in Mackey 2002).

This area is which researcher in phenomenology separated the conscious from intermediate and background. In completion of definition of National Communication Association a media literate person, can coding this area and creating a concept in addition to critical understanding of words and pictures. W. James Potter (2013) in his paper (review of literature on media literacy) classified definitions and brought up media literacy interventions in order to explain this phenomenon.

If we try to close linguistic distinctions of philosophy and communication, we will see their both efforts are about the conscious. The tools of modern contemporary live, at last now, is made necessary the need of phenomenology to precisely recognize input data for processing.

David Buckingham believes the aim of media literacy surely leads to media literacy and development of critical conscious and tries to interpret conscious with explaining its Necessities, beings, what and how.

Despite many definitions Media literacy is not just a understanding based on skill for analysis media product (Shokrkhah 2009). If we believe that media makes lots of reality without we even experience or watch them, then clear up the role of aware media as contemporary phenomenon (Tanjong,, Enoh; Gaddy, Gary D. (1994). "The Agenda-Setting Function of the International Mass Media: The Case of Newsweek in Nigeria". Africa Media Review).

Then the role of awareness of media literacy as a contemporary phenomenon becomes clearer.

Nowadays media have involved in an epidemic and a general concept that practically impress all of human experiences, and from this perspective, media literacy is a gateway for analysis, feedback and produce message that practically makes perception of the environment. Approaches, goals, needs and history of this phenomenon and even related theories helps to explaining the identity of this phenomenon in the phenomenology that remains no doubt that in modern area, media literacy is gateway of understanding every phenomenon.

\section{References}

Armstrong, M., (2010). Armstrong's Essential Human Resource Management Practice. London: Kagon Page.

Barritt, L. S., Beekman, T. Bleeker, H. \& Mulderij, K. (1983). A handbook for phenomenological research. Ann Arbor: University of Michigan Press.

Bate, P., Robert, G. \& Lavis, P. (2007, 37). Bringing User Experience to Healthcare Improvement: The Concepts, Methods and Practices of Experience-Based Design. Radcliffe Publishing.

Bernet, Rudolf; Kern, Iso ;and Marbach Eduard, Introduction to Husserlian Phenomenology , Evantson IL; Northwestern University Press 1993., 235 - 244

Buckingham, David. (2003). Media Education: Literacy, Learning and Contemporary Culture.

Campbell, J. (2011. Introduction to Methods of Qualitative Research: Video Series. Ft. Lauderdale, Florida, U.S.A.

Campbell, J. (n.d.). Introductive Methods to Qualitative Research: Course Notes. Retrieved October 6, 2011, from jasonjcampbell.org: http://www.jasonjcampbell.org/uploads/Methods_of_ Qualitative_Research_and_Inquiry.pdf

Creswell, J. (2007). Qualitative Inquiry and Research Design: Chosing Among Five Approaches 2nd Edition. Thousand Oaks: Sage Publications.

Derrida, Jacques. (1973). Speech and Phenomena and Other Essays on Husserl's Theory of Signs. Evanston: Northwestern UP.

Derrida, Jacques. (2003). The Problem of Genesis in Husserl's Philosophy. Trans. Marian Hobson. Chicago: U of Chicago.

Dilthey, W. (1977). Descriptive psychology and historical understanding (R. Zaner \& K. Heiges, Trans.). The Hague: Martinus Nijhoff. (Original publication 1894). 
Giorgi, A. (1971). Phenomenology and experimental psychology. In A. Giorgi, W. Fischer, \& R. von Eckartsberg (Eds.), Duquesne studies in phenomenological psychology (pp.6-29). Pittsburgh: Duquesne University Press.

Giorgi, A. (1997). The theory, practice, and evaluation of the phenomenological method as a qualitative research procedure. Journal of Phenomenological Psychology, 28, 236-60.

Hegel, G. W. F. (1967). The phenomenology of mind (J. B. Baillie, Trans.). New York: Harper \& Row. (Original work published 1910).

Hegel, G. (2010). Science of Logic. Trans. George di Giovanni. Cambridge: Cambridge UP.

Heidegger, E. (1931/1962). Being and time (J. Macquarrie\& E. Robinson, Trans.). New York: Harper \& Row. (Original work published 1931).

Heidegger, Martin. (1982). The Basic Problems of Phenomenology. Trans. Albert Hofstadter. Bloomington: Indiana Press.

Hitchcock, L., Methodology in Computing Education: A Focus on Experiences. $19^{\text {th }}$ Annual NACCO Conference. Wellington New Zealand: N.p., 2006.

Husserl, E. (1965). Phenomenology and the crisis of philosophy (Q. Lauer, Trans.). New York: Harper \& Row. (Original work published 1936).

Husserl, E. (1970). The crisis of European sciences and transcendental phenomenology: An introduction to phenomenological philosophy. Evanston: Northwestern University Press. (Original published 1935.)

Husserl, Edmund. (1991). Cartesian Meditations: An Introduction to Phenomenology. Trans. Dorion Cairns. Boston: Kluwer.

Karlsson, G. (1993). Psychological qualitative research from a phenomenological perspective. Stockholm: Almqvist \& Wiksell.

Keller P. , Husserl and Heidegger on Human Experience, 2007.

Kuhn, T. (1970). The structure of scientific revolution. Chicago: University of Chicago Press.

Kuhn, T. (1991). The natural and the human sciences. In D. Hiley, J. Bohman, \& R. Shusterman (Eds.), The interpretive turn: Philosophy, science, culture (pp. 17-24). Cornell University Press: London.

Levinas, Emmanuel. The Theory of Intuition in Husserl's Phenomenology. 2nd ed. Trans. André Orianne. Evanston: Northwestern UP, 1995. Print.

McCombs and Maxwell. (2004). Setting the Agenda: The Mass Media and Public Opinion.

McGowan, Todd. (2013). The Presence of Phenomenology: Hegel and the Return to Metaphysics. Mosaic: a Journal for the Interdisciplinary Study of Literature 46,(1) : 95-111.

Moran, D., Edmund Husserl: Founder of Phenomenology. Cambridge and Malden, Massachusetts: Polity Press, 2005.

Pažanin A. „Etika i politika“; Prilog praktičnoj filozofiji,Hrvatsko filozofsko društvo ,Zagreb ,2011. $411-437$

Potter, W., James. (2013). Review of Literature on Media Literacy.

Rockmore T."Kant and Phenomenology, University of Chicago Press 2011.

Stake, R.E., 2010. Qualitative Research: Studying How Things Work. New York: The Guilford Press.

Stanford Encyclopedia of Philosophy, Phenomenology, 1Th Edition, 2003. substantive revision 2013.

Tanjong, Enoh, Gaddy, Gary, D., (1994). The Agenda Setting Function of the International Mass Media: The case of Newsweek in Nigeria. Africa Media Review.

Taylor, C. (1980). Understanding in the human sciences. Review of Metaphysics, 34, 25-38

Van den Berg, J. (1999). Historical phenomenology or method of change. 16 th Annual Symposium of the Simon Silver Phenomenology Center. Pittsburgh: Duquesne University Press.

Willis, J. (2007). Foundations of Qualitative Research: Interpretive and Critical Approaches. Thousand Oaks: Sage Publications.

Winkler, Rafael; Botha, Catherine F. (2013). Phenomenology and its Futures. South African Journal of Philosophy, 32(4): 291-294.

Zizek, Slavoj. (2010). Living in the End Times. New York: Verso. 